\title{
Is type 2 diabetes mellitus a significant problem in European adolescents?
}

\author{
Éva Erhardt and Dénes Molnár
}

Department of Paediatrics, Medical Faculty, University of Pécs, Hungary

Abstract

\begin{abstract}
The rapidly rising incidence of type 2 diabetes mellitus in young patients is well known in North America, especially in some minorities. Population-based data suggest that the epidemic of paediatric obesity is being followed by an increase in type 2 diabetes mellitus, but for European countries there are such no populationbased incidence and prevalence data. From the available data the magnitude of the problem in the European Caucasian population seems to be much less than in North America. Although type 2 diabetes mellitus is still rare in childhood, an increasing rate is expected paralleling the growing rates of obesity; therefore, children and adolescents with a substantial risk for the presence or development of type 2 diabetes should be screened. Among Hungarian obese adolescents impaired glucose tolerance was found in $17.3 \%$ and type 2 diabetes mellitus in $1.9 \%$ of children. Any feature or condition associated with insulin resistance or hyperinsulinaemia should alert health-care providers to screen young people at increased risk for type 2 diabetes mellitus.
\end{abstract}

Keywords: adolescents; impaired glucose tolerance; type 2 diabetes mellitus

Received: 15 Apr. 2004; Revised: 28 Jun. 2004; Accepted: 28 Jun. 2004

\section{Introduction}

Although type 1 diabetes remains the main form of diabetes in the young, the much less common inherited forms of diabetes, as well as type 2 diabetes mellitus (T2DM), can also present in early life. T2DM in children and adolescents is regarded as an emerging problem; however, there are few reliable reports of its true population prevalence or its prevalence in obese children.

Population-based data suggest that the epidemic of paediatric obesity is being followed by an increase in T2DM. The American Diabetes Association (ADA) has issued a consensus statement on T2DM in young people, stating that $8-45 \%$ of newly diagnosed DM children had non-immunemediated diabetes (1).

The phenomenon of a rapidly rising incidence of T2DM in young patients is well known in North America (2). T2DM now accounts for as many as $8-46 \%$ of new cases of paediatric diabetes and affects up to $5 \%$ of adolescents in some Native American tribes $(2,3)$. However, the emergence of T2DM in children is not limited to that country. Among Japanese junior high school-aged youngsters (4) the incidence of T2DM increased from 7.2 per 100000 in $1976-1980$ to 13.9 per 100000 in
1991-1995. The mean annual incidence of T2DM in Australian children below the age of 16 was 2.5 per 100000 in 2001/02 (5).

As the childhood population becomes increasingly overweight, T2DM may be expected to occur in younger, prepubertal children. The young age at presentation exposes these patients to a high risk of complications in adult life.

\section{Epidemiology of type 2 diabetes mellitus in children in Europe}

The MEDLINE database on T2DM in children and adolescents was searched between January 1998 and January 2004 using the keywords: type 2 diabetes mellitus, non-insulin dependent diabetes mellitus, children, adolescence, Europe. A questionnaire was also distributed among European Childhood Obesity Group (ECOG) representatives from 14 European countries, which included several questions concerning the prevalence, risk factors and complications of childhood obesity. One of them was "Is the increased prevalence of overweight and obesity associated with an increase in type 2 diabetes? Is it possible to quantify this?" The quality of epidemiological data regarding the prevalence of T2DM among adolescents varies considerably. 
In European countries, publications on the prevalence of T2DM in young people are anecdotal and there are no population-based incidence and prevalence data.

According to the data of the Pan-Birmingham Diabetes Advisory Group (6) the first case of childhood T2DM in Europe was diagnosed in 1993, and up to 200117 other patients were reported, 15 of whom were of South Asian origin. Whether the emergence of T2DM in children from ethnic minorities has implications for the wider paediatric population is unclear.

Drake et al., from Bristol, UK (7) reported four white adolescents who presented with T2DM associated with significant obesity [body mass index $(\mathrm{BMI})>+3$ standard deviation scores (SDS)]. Three of them were female and two had acanthosis nigricans and a family history of diabetes.

In an Italian study (8) based on 710 grossly obese children and adolescents of European origin, the prevalence of T2DM was $0.1 \%$ and that of impaired glucose tolerance (IGT) was $4.5 \%$.

Wabitsch et al. (9) recently published a report on the prevalence of T2DM and impaired glucose regulation in Caucasian obese children living in Germany. T2DM was present in eight $(1.5 \%)$ of the patients examined. All of them were of pubertal age and the male to female ratio was 1:3. Analysis of the multicentre database from 148 paediatric diabetes centres from Germany and Austria (10) revealed $130(0.6 \%)$ children of Caucasian origin with T2DM compared with 19796 patients with type 1 diabetes. Patients with T2DM were predominantly female, significantly older at diagnosis and more overweight.

Thirty-one $(0.5 \%)$ cases of T2DM out of approximately 6000 children with diabetes were found in Sweden (11). Fifty per cent of them were from ethnic minorities known to have a high incidence of T2DM and the male to female ratio was 1:2.

Data on T2DM incidence in children from eastern and central Europe are even scarcer. In a multicentre trial on metformin in paediatric patients with T2DM (12), besides 62 children from the USA, 16 children from Russia, four from Ukraine, two from Belarus and one from Poland were included. Their age ranged from 10 to 17 years and over $80 \%$ were obese or overweight.

In a study by the present group (13), an oral glucose tolerance test (OGTT) was performed in 289 obese (mean $\mathrm{BMI} \pm \mathrm{SD}: 31.1 \pm 4.6 \mathrm{~kg} / \mathrm{m}^{-2}$ ) adolescents (mean age \pm SD: $12.9 \pm 2.7$ years), of whom IGT was found in $50(17.3 \%)$ and T2DM in five $(1.9 \%)$ children. In another study in northeastern Hungary, IGT was found in $18 \%$ and T2DM in $1.1 \%$ of obese children. Thus, the prevalence of IGT and T2DM was similar in the south-western and north-eastern parts of the country.

Although the prevalence and incidence of T2DM is increasing, the crude prevalence of the disease compared with type 1 diabetes mellitus in children aged under 18 years is still negligible $(6,14)$ (Table 1).

\section{Clinical aspects of type $\mathbf{2}$ diabetes mellitus}

Diagnosis of T2DM in affected children is very difficult, because most paediatric patients with T2DM are asymptomatic and have atypical presentations, with classical features of both type 1 and type 2 diabetes appearing in some obese children $(15,16)$. They are usually identified when glucosuria or hyperglycaemia is found on routine testing or during assessment of their obesity. Some may have non-specific symptoms such as vaginal or penile moniliasis. Moreover, individuals with immunemediated type 1 diabetes may have clinical presentations indistinguishable from those of patients with non-immune-mediated T2DM, and they are often diagnosed as having type 1 diabetes. A small number of children with T2DM may suffer from polyuria and polydipsia, and some develop ketoacidosis $(1,3,15)$.

According to the ADA (1) the risk factors for developing T2DM in children are obesity/overweight, family history of T2DM, ethnic minority, puberty, female gender and features of "syndrome X". In the obesity-diabetes relationship, two factors are mentioned as the major components: insulin resistance and insulin deficiency. Both insulin resistance and $\beta$-cell failure are present in fully developed T2DM $(17,18)$. IGT refers to be an intermediate stage in the natural history of T2DM. In the 1960s and 1970s several studies investigated the status of carbohydrate tolerance in children with obesity (19-21). In a recent, multiethnic cohort of 167 American obese children and adolescents (using OGTT) IGT was detected in $21 \%$ of obese adolescents (BMI: $35.5 \pm 1.0$ ) and silent T2DM was identified in $4 \%$ of them (22). In a study by the present group the prevalence of IGT [criteria of Guthrie (23)] was 50\% among obese Hungarian 
Table I. Comparative data on prevalence of diabetes mellitus in children

\begin{tabular}{llll}
\hline & $\begin{array}{l}\text { Age } \\
\text { (years) }\end{array}$ & $\begin{array}{l}\text { Type I } \\
\text { diabetes mellitus }\end{array}$ & $\begin{array}{l}\text { Type 2 } \\
\text { diabetes mellitus }\end{array}$ \\
\hline Ehtisham et al. (6) & 18 years & $1.818 / 1000$ & $0.038 / 1000$ \\
Feltbower et al. (14) & $0-30$ years & $2.15 / 1000$ & $0.13 / 1000$ \\
\hline
\end{tabular}

children (24). As mentioned above, according to recent data, the prevalence of IGT [criteria of ADA and WHO (25)] was around $18 \%$ in obese children in two different parts of Hungary. Unfortunately, the results of earlier investigations concerning to IGT cannot be compared with recent results, since the applied glucose loads and definitions for IGT are different.

In adults it may take several decades for fullblown T2DM to develop. Jallut et al. (26) examined 33 obese adults. Among them nine (27\%) had IGT and $11(34 \%)$ had T2DM at the beginning, and during a 6 year follow-up IGT developed in four patients, while T2DM developed in two patients. Tuomilehto et al. (27) compared a control and an intervention (diet and physical exercise) obese group of adults $(n=522)$. During a 6 year follow-up T2DM developed in $6 \%$ of the controls and in $3 \%$ of the intervention group.

It is not known how many children with IGT develop T2DM, but it is likely that disease progresses from IGT more rapidly then in adults, particularly during adolescence, when there is transient insulin resistance. When young people with T2DM were compared with controls matched for age, gender and stage of maturation, stimulated C-peptide was significantly lower, whereas glucagon responses did not differ. However, plasma glucagon was significantly higher in long-term than in shortterm T2DM patients (28). Relative hypoinsulinaemia and hyperglucagonaemia therefore seem to represent pancreatic $\beta$ - and $\alpha$-cell dysfunction in children with T2DM.

Disorders associated with insulin resistance such as acanthosis nigricans, polycystic ovarian syndrome and hypertension are also common in young people with T2DM (29-31), but they may be associated with obesity per se.

Few data exist on long-term follow-up of children and adolescents with T2DM, but data from Japanese and Indian children show the presence of severe complications at follow-up such as incipient retinopathy and microalbuminuria (32). In adults, the UKPDS (33) showed a logarithmic association of the hazard ratio for all diabetes endpoints against glycosylated haemoglobin $\left(\mathrm{HbA}_{1 \mathrm{c}}\right)$.

These data indicate that there is a great need for screening to identify asymptomatic individuals who are likely to have diabetes. Consistent with screening recommendations for adults, only children and young people with substantial risk for the presence or the development of T2DM should be tested. The risk factors listed by the ADA (1) are presented in Table 2. In summary, any feature or condition associated with insulin resistance or hyperinsulinaemia should alert health-care providers to screen young people at increased risk for T2DM.

\section{Treatment of type $\mathbf{2}$ diabetes mellitus}

The treatment of children and adolescents who have T2DM is as demanding as in adults. Diet and exercise are the main cornerstones of therapy (34), but they are seldom successful alone, as they require high motivation and lifestyle changes. Because obesity is one of the risk factors for T2DM, it is imperative that effective treatment is developed. Therapeutic strategies include lifestyle and behaviour modification, nutrition education, and psychological and family therapy interventions. Exercise and physical activity have an effect on body weight reduction as well as on insulin sensitivity.

Asymptomatic children identified at routine testing should be counselled on the necessary lifestyle changes. Because obesity is the major problem in most adolescents with T2DM, dietetic advice is

Table 2. Testing for type 2 diabetes in children

\section{Criteria $^{\mathrm{a}}$}

Overweight (body mass index $>85$ th percentile for age and gender, weight for height $>85$ th percentile or weight $>120 \%$ of ideal for height) Plus any two of the following risk factors:

Family history of type 2 diabetes in first or second degree relative

Race/ethnicity (American Indian, African-American, Hispanic, Asian/Pacific Islander)

Signs of insulin resistance or conditions associated with insulin resistance (acanthosis nigricans, hypertension, dyslipidaemia, polycystic ovarian syndrome) Age of initiation of testing: age 10 years or at onset of puberty

Frequency: every 2 years

Test: fasting plasma glucose preferred ${ }^{b}$

${ }^{\text {a }}$ According to the American Diabetes Association ( $\mathrm{I}$ ). Clinical judgement should be used to test for diabetes in high-risk patients who do not meet these criteria. b In the authors' experience, the performance of an oral glucose tolerance test is much more sensitive. 
mandatory, although calorie intake should not be too restricted to ensure normal growth and pubertal development. Patients should be encouraged to increase their physical activity or at least to decrease inactivity, as most of them have lifestyles characterized not only by high fat intake but also by minimal physical activity (35). If the changes in lifestyle are accepted and adherence is good they may be the only recommendations for asymptomatic patients. In a Hungarian study, after 6 months of lifestyle and dietary changes the metabolic status of obese children with IGT and T2DM had improved (13). The changes in metabolic parameters are shown in Table 3. In four adolescents with T2DM, the OGTT and anthropometric measurements were also repeated, and the same changes could be seen in body weight, plasma glucose, insulin and homoeostasis model assessment levels as for the children with IGT.

However, if the treatment goals are not achieved and the patient fasting blood glucose and $\mathrm{HbA}_{1 \mathrm{c}}$ are elevated, pharmacological therapy should be considered. Insulin treatment remains an important and effective mode of therapy in children (36), and is the only initial treatment recommended for those who present with severe hyperglycaemia or diabetic ketoacidosis (15). Until recently, insulin was the only therapy approved by the Food and Drug Administration (FDA) for patients with T2DM under the age of 18 years. Recently, metformin has been approved by FDA for use in children between 10 and 16 years, and has been recommended by the ADA (1) as a first line oral agent for treatment of T2DM in children. Rare complications of its use are

Table 3. Anthropometric data and metabolic parameters in obese children with impaired glucose tolerance after a 6 month diet and lifestyle changes $(n=32)$

\begin{tabular}{|c|c|c|}
\hline & Ist examination & $\begin{array}{l}\text { 2nd examination } \\
\text { (6 months later) }\end{array}$ \\
\hline Body weight (kg) & $77.6 \pm 24.1$ & $76.4 \pm 22.0$ \\
\hline Body height $(\mathrm{cm})$ & $157.3 \pm 30.1$ & $160.9 \pm 15.3$ \\
\hline Body mass index $\left(\mathrm{kg} \mathrm{m}^{-2}\right)$ & $30.4 \pm 4.9$ & $29.0 \pm 4.4^{* * *}$ \\
\hline Plasma glucose $120 \mathrm{~min}\left(\mathrm{mmol} \mathrm{I}^{-1}\right)$ & $8.6 \pm 0.7$ & $7.0 \pm 1.2 *$ \\
\hline Plasma insulin $0 \min \left(\mu \mathrm{l} \cup \mathrm{ml}^{-I}\right)$ & $29.1 \pm 9.2$ & $18.8 \pm 8.0 *$ \\
\hline Plasma insulin $120 \mathrm{~min}\left(\mu \mathrm{lU} \mathrm{ml}{ }^{-1}\right)$ & $168.7 \pm 92.9$ & $117.4 \pm 85.9 *$ \\
\hline Homoeostasis model assessment & $6.7 \pm 3.7$ & $4.9 \pm 3.3^{*}$ \\
\hline
\end{tabular}

Data are shown as mean \pm SD.

0 and 120 min: time at which blood was taken during the oral glucose tolerance test.

${ }^{*} p<0.001,{ }^{*}{ }^{*} p<0.05$ lactic acidosis and diarrhoea. Sulfanylureas may exhaust the endogenous insulin reverse. $\alpha$-Glucosidase inhibitors, which retard carbohydrate absorption, are not recommended for children as they produce flatulence and soft stools. Sulfanylureas, meglitinides and thiazolidinediones have not been approved for use in children.

Metformin reduces fasting blood glucose and lowers insulin resistance, probably by its effect on hepatic glucose output (37). It is also reduces food intake and may be helpful in decreasing obesity. In a group of obese adolescents with fasting hyperisulinaemia and a family history of T2DM, 6 months of metformin therapy resulted in a decline in fasting blood glucose and insulin, and was accompanied by a small but statistically significant reduction in BMI SDS, although the patients' diet was not restricted (38). It is relatively safe, as it does not cause hypoglycaemia. In a 16 week double-blind placebo-controlled study metformin resulted in significantly lower fasting plasma glucose and $\mathrm{HbA}_{1 \mathrm{c}}$ in a group of children with new-onset T2DM (39). According to Zuhri-Yafi et al. (40), metformin appeared to provide effective therapy for T2DM in children, in that it permits reduction of insulin dosing in the group treated with insulin and metformin together. Those patients who could be treated with metformin alone had a greater reduction in their $\mathrm{HbA}_{1 \mathrm{c}}$ levels than patients who required insulin and metformin together, although long-term metformin monotherapy did not seem to be sufficient.

Initiation of insulin therapy is recommended for the patient who is symptomatic at presentation, with evidence of severe insulin deficiency, elevated blood glucose and $\mathrm{HbA}_{1 \mathrm{c}}$ with or without ketonuria.

At present few drugs are approved by the FDA for the treatment of adult obesity and only two of these medications (sibutramine and orlistat) are widely used in clinical practice. In childhood there is only very limited experience with antiobesity drugs and these two drugs are not approved for adolescent treatment. Orlistat binds to gastrointestinal lipases and causes partial inhibition of fat resorption from the gut (41). In contrast, sibutramine causes a centrally mediated increase in satiety and energy expenditure (42). When combined with a hypocaloric diet, both drugs lead to a moderate additional weight loss within 6 months $(41,42)$. Two studies $(43,44)$ demonstrated that orlistat treatment 
is well tolerated in obese adolescents and has a side-effect profile similar to that in adults, but its true benefit over conventional therapy remains to be determined in placebo-controlled trials.

According to the data in the literature, lifetime management strategies in children with T2DM will probably be as complex as in adults.

\section{Conclusions}

On the basis of the available data, the prevalence of T2DM in Caucasian children and adolescents is much lower than reported in other races, but more representative, population-based surveys are needed. The presence of IGT and chemical diabetes was reported as early as the 1960s and 1970s; however, comparison of these data with recent figures is not really possible since the glucose load applied and the criteria for IGT and T2DM were different. T2DM is clearly a multifactorial and heterogeneous disorder, so preventive measures must be based on the modification of several potential risk factors. Assuming that T2DM is preventable, there are two components to primary prevention. First, a population strategy is needed, to alter the lifestyle and environmental determinants of T2DM. Secondly, a high-risk strategy is needed for screening individuals at especially high risk for $\mathrm{T} 2 \mathrm{DM}$ and providing preventive care.

\section{Acknowledgements}

Support was provided by a Hungarian National Research Grant (OTKA T033066/2000), the Hungarian Ministry of Welfare (ETT 113/2003) and the Agency for Research Fund Management and Research Exploitation (BIO-00023/2002).

\section{References}

1. American Diabetes Association. Type 2 diabetes in children and adolescents. Pediatrics 2000; 105: 671-80.

2. Pinhas-Hamiel O, Dolan LM, Daniels SR, Standiford D, Khoury PR, Zeiter P. Increased incidence of noninsulin-dependent diabetes mellitus among adolescents. J Pediatr 1996; 128: 608-15.

3. Fagot-Campagna A, Pettitt DJ, Engelgau MM, Burrows NR, Geiss LS, Valdez R, et al. Type 2 diabetes among North American children and adolescents: an epidemiological review and a public health perspective. J Pediatr 2000; 136: 664-72.

4. Kitagawa T, Owada M, Urakami T, Yamauchi K. Increased incidence of non-insulin dependent diabetes mellitus among Japanese schoolchildren correlates with increased intake of animal protein and fat. Clin Pediatr 1998; 37: 111-5.
5. Craig ME, Bryoda V, Crock P, Howard NJ. The epidemiology of type 2 diabetes in NSW and the ACT Australia 2001-2002 (Abstract). J Pediatr Endocrinol Metab 2003; 16(Suppl 4): 922.

6. Ehtisham S, Kirk J, McEvilly A, Shaw N, Jones S, Rose $\mathrm{S}$, et al. Prevalence of type 2 diabetes in children in Birmingham. Br Med J 2001; 322: 1428-9.

7. Drake AJ, Smith A, Betts PR, Crowne EC, Shield JPH. Type 2 diabetes in obese white children. Arch Dis Child 2002; 86: 207-8.

8. Invitti C, Guzzaloni G, Giraldinini L. Prevalence and concomitants of glucose intolerance in European obese children and adolescents. Diabetes Care 2003; 26: $118-$ 24.

9. Wabitsch M, Hauner H, Hertrampf M, Muche R, Hay $\mathrm{B}$, Mayer $\mathrm{H}$, et al. Type II diabetes mellitus and impaired glucose regulation in Caucasian children and adolescents with obesity living in Germany. Int $\mathbf{J}$ Obes Relat Metab Disord 2004; 28: 307-13.

10. Grabert M, Krause U, Rami B, Scober E, Schweiggert F, Thon A. Prevalence and clinical characteristics of patients with non-type-1-diabetes in pediatric age range: analysis of multicenter database including 20401 patients from 148 centers in Germany and Austria (Abstract). Diabetologia 2003; 46(Suppl 2): 26.

11. Zachrisson I, Tibell C, Bang P, Ortquist E. Prevalence of type 2 diabetes among known cases of diabetes aged 0 18 years in Sweden (Abstract). Diabetologia 2003; 46(Suppl 2): 56.

12. Jones KL, Arslanian S, Peterkova VA, Park JS, Tomlison MJ. Effect of metformin in paediatric patients with type 2 diabetes: a randomised controlled trial. Diabetes Care 2002; 25: 89-94.

13. Erhardt E, Csernus K, Felszeghy E, Ilyés I, Molnár D. Impaired glucose tolerance and type 2 diabetes in obese children (Abstract). Int $\mathbf{J}$ Obes Relat Metab Disord 2003; 27: S24.

14. Feltbower RG, McKinney PA, Campbell FM, Stephenson CR, Bodansky HJ. Type 2 and other forms of diabetes in 0-30 year olds: a hospital based study in Leeds, UK. Arch Dis Child 2003; 88: 676-9.

15. Scott CR, Smith JM, Cradock MM, Pihoker C. Characteristics of youth-onset noninsulin-dependent diabetes mellitus and insulin-dependent diabetes mellitus at diagnosis. Paediatrics 1997; 100: 84-90.

16. Rapaport R, Wallach E, Greig F, Iazetti L. Diabetes mellitus: type 1 or type 2? J Pediatr 2001; 138: 612.

17. Kahn SE. The importance of $\beta$-cell failure in the development and progression of type 2 diabetes. J Clin Endocrinol Metabol 2002; 86: 47-58.

18. Felber JP, Golay A. Pathways from obesity to diabetes. Int J Obes 2002; 26(Suppl 2): S39-45.

19. Paulsen E, Richendorfer L, Ginsberg-Fellner F. Plasma glucose, free fatty acids, and immunoreactive insulin in 66 obese children. Diabetes 1968; 17: 261.

20. Chiumello G, Guercio MJ, Garnelutti M, Bidone G. Relationship between obesity, chemical diabetes, and beta pancreatic function in children. Diabetes 1969; 18: 238 . 
21. Drash A. Relationship between diabetes mellitus and obesity in the child. Metabolism 1973; 22: 337-44.

22. Sinha R, Fisch G, Teague B, Tamborlane WV, Banyas B, Allen K, et al. Prevalence of impaired glucose tolerance among children and adolescents with marked obesity. N Engl J Med 2002; 346: 802-10.

23. Guthrie RA, Guthrie DW, Murthy DYN. Standardization of oral glucose tolerance test and criteria for the diagnosis of chemical diabetes in children. Metabolism 1973; 22: 275-82.

24. Molnár D. Insulin secretion and carbohydrate tolerance in childhood obesity. Klin Padiatr 1990; 202: 131-5.

25. Expert Committee on the Diagnosis and Classification of Diabetes Mellitus: Report of the Expert Committee on the Diagnosis and Classification of Diabetes Mellitus. Diabetes Care 1999; 22(Suppl 1): S5-19.

26. Jallut D, Golay A, Molnger R, Frascurolo P, Schutz Y, Jequier E, Felter JP. Impaired glucose tolerance and diabetes in obesity: a 6-year follow-up study of glucose metabolism. Metabolism 1990; 39: 1068-75.

27. Tuomilehto J, Lindstrom J, Eriksson JG, Valle TT, Hamalainen H, Ilanne-Oarikka P, et al. Finnish Diabetes Prevention Study Group. Prevention of type 2 diabetes mellitus by changes in lifestyle among subjects with impaired glucose tolerance. N Engl J Med 2001; 344: $1343-50$.

28. Umpaichitra V, Bastian W, Taha D, Banerji A, Avruskin T, Castells S. C-peptide and glucagons profiles in minority children with type 2 diabetes mellitus. J Clin Endocrinol Metab 2001; 86: 1605-9.

29. Nguyen TT, Keil MF, Russel DL, Pathomvanich A, Uwaifo GI, Sebring NG, et al. Relation of acanthosis nigricans to hyperinsulinemia and insulin sensitivity in overweight Africa American and white children. J Pediatr 2001; 138: 474-80.

30. Kerem N, Guttmann H, Hochberg Z. The autosomal dominant trait of obesity, acanthosis nigricans, hypertension, ischemic heart disease and diabetes type 2 . Horm Res 2001; 55: 298-304.

31. Levy VD, Danadian K, Witchel SF, Arslanian S. Early metabolic abnormalities in adolescent girls with polycystic ovarian syndrome. J Pediatr 2001; 138: 38-44.

32. Brosnan ChA, Maininger JC, Swank PR, Reyes LR, Brosnan PG. Blood pressure profiles in adolescents with recently diagnosed type 2 diabetes (Letter to the Editor). Diabetes Care 2002; 25: 2354.

33. Stratton IM, Adler AI, Neil HA, Matthews DR, Manley SE, Cull CA, et al. Association of glycaemia with macrovascular and microvascular complications of type 2 diabetes (UKPDS 35): prospective observational study. Br Med J 2000; 321: 405-12.
34. Glaser NS. Non-insulin-dependent diabetes mellitus in children and adolescents. Pediatr Clin N Am 1997; 44: 307-37.

35. Pinhas-Hamiel O, Standiford D, Hamiel D, Dolan LW, Cohen R, Zeiter PS. The type 2 family. A setting for development and treatment of adolescent type diabetes mellitus. Arch Pediatr Adolesc Med 1999; 153: 1063-7.

36. Dabelea D, Pettit DJ, Jones KL, Arslanian SA. Type 2 diabetes mellitus in minority children and adolescents: an emerging problem. Endocrinol Metab Clin N Am 1999; 28: 709-29.

37. Gunton J, Delhanty PJ, Takahashi SI, Baxter R. Metformin rapidly increases insulin receptor activation in human liver and signals preferentially through insulin-receptor substrate-2. J Clin Endocrinol Metab 2003; 88: 1323-32.

38. Freemark M, Bursey D. The effects of metformin on body mass index and glucose tolerance in obese adolescents with fasting hyperinsulinemia and family history of type 2 diabetes. Pediatrics 2001; 107: E55-69.

39. Jones K, Arslanian S, McVie R, Tomlison M, Park JS, Study Group - Metformin Pediatric. Metformin improves glycemic control in children with type 2 diabetes. Diabetes 2000; 49: A75.

40. Zuhri-Yafi MI, Brosnan PG, Hardin DS. Treatment of type 2 diabetes mellitus in children and adolescents. $\mathbf{J}$ Clin Endocrinol Metab 2002; 15: 541-6.

41. Muls E, Kolanowski J, Sheen A, Van Gaal L. The effects of orlistat on weight and on serum lipids in obese patients with hypercholesterolemia: a randomised, double-blind, placebo-controlled, multicenter study. Int $\mathrm{J}$ Obes Relat Metab Disord 2001; 25: 1713-21.

42. Wirth A, Krause J. Does long-term use of sibutramine result in continued weight loss in short-term responders? JAMA 2001; 286: 1331-9.

43. Norgren S, Danielsson P, Jurold R, Lötborn M, Marcus C. Orlistat treatment in obese prepubertal children: pilot study. Acta Paediatr 2003; 92: 666-70.

44. McDuffie JR, Calis KA, Uwaifo GI, Sebring NG, Fallon EM, Hubbard VS, Yanovski JA. Three-month tolerability of orlistat in adolescents with obesity-related comorbid conditions. Obes Res 2002; 10: 642-50.

\footnotetext{
Éva Erhardt

Department of Paediatrics

Medical Faculty

University of Pécs

HU-7623 Pécs, József A. u. 7

Hungary

Tel: +3672535900

Fax: +3672535971

E-mail: eva.erhardt@aok.pte.hu
} 